\title{
Decomposition of Retained Austenite in a High-Speed Steel GPM A30
}

\author{
T.H. Yu, C.Y. Chen, and J.R. Yang
}

(Submitted February 8, 2006)

\begin{abstract}
The effect of tempering on the decomposition of retained austenite in a powder metallurgy (PM) high-speed steel, GPM A30, has been monitored with a high-speed dilatometer. The corresponding microstructures of specimens with different tempering cycles have been investigated by a combination of scanning electron microscopy and analytical transformation electron microscopy. The as-quenched structure of the steel studied is composed of retained austenite, untempered martensite, and carbides. The results indicate that the complete transformation of retained austenite can be more nearly accomplished by double or triple tempering cycles than by a single long-time cycle. The possible transformation mechanism for the decomposition of retained austenite during multiple tempering cycles is attributed to the invariant-planestrain of the prior martensitic transformation extending accommodation defects to the adjacent retained austenite, which favors further transformations in the subsequent tempering operations.
\end{abstract}

Keywords carbide transformation, decomposition of retained austenite, plate martensite, powder metallurgy (PM) high-speed steel, thermal dilatometer

\section{Introduction}

High speed steels are complex iron-base alloys of carbon, chromium, vanadium, molybdenum, tungsten, or combinations thereof, and substantial amounts of cobalt. Since the high speed steels have high carbon and high alloy contents, their typical asquenched structure is a mixture of twinned plate martensite, retained austenite, and undissolved carbides. If the chosen tempering process for these types of steels ensures the elimination of all the retained austenite and tempers all areas of martensite, an attractive combination of strength, toughness, and size-stability in application can be obtained (Ref 1-7). The standard heat treatment process suggested (Ref 8) is to use (i) an oil or air quench and (ii) a double or triple repeated tempering treatment with cooling to room temperature. Although the conventional tempering of martensite in asquenched low-carbon steels can be divided into five distinct stages (Ref 9), the actual mechanism of tempering in these types of steels is still not clear.

There has been intensive research work on retained austenite and lath martensite in low-carbon alloy steels. However, little TEM research work has been carried out on twinned plate martensite with retained austenite in high-carbon alloy steels (Ref 10). It is naturally very difficult to produce electrontransparent samples for TEM (because the high-carbon alloys are quite brittle), but TEM investigation continues to assume greater significance in research.

T.H. Yu, C.Y. Chen, and J.R. Yang, Department of Materials Science and Engineering, National Taiwan University, Taipei, Taiwan, ROC. Contact e-mail: d89542011@ntu.edu.tw.

GPM A30* is a high-carbon grade of commercial P/M high speed steel and is widely used in such applications as metal cutting tools and metal forming dies. In this work, dilatometric experiments were performed to investigate the tempering response in quench-treated specimens of GPM A30 high speed steel. The resulting scanning electron micrographs and transmission electron micrographs were examined to elucidate the microstructural evolution.

\section{Experimental Procedure}

The as-received material was a commercially wrought GPM A30 high speed steel bar (with a diameter of $42 \mathrm{~mm}$ ) produced by Gloria Material Technology Corporation through four folded forging of a cast slab at $1150{ }^{\circ} \mathrm{C}$, then hot rolling and annealing at $850{ }^{\circ} \mathrm{C}$, followed by furnace cooling to ambient temperature. The chemical composition was identified by Spark-AES (JOBIN YVON JY48), carbon-sulfur determinator (LECO CS-244), and nitrogen-oxygen determinator (LECO TC-136). The detailed chemical composition of the steel is listed in Table 1.

All the tempering thermal cycles in this work were performed on a Dilatronic III RDP deformation dilatometer from Theta Industries, Inc. The dilatometer was interfaced with a computer workstation (PDP 11/55 central processor) for analysis of the resulting data. The software package (provided by Theta Industries, Inc.) provides a flexible and complete environment in which to execute multiple tempering cycle experiments. The length, time and temperature information was recorded in microsecond intervals, and the level of vacuum could be maintained at $10^{-5}$ torr $\left(10^{-3} \mathrm{~Pa}\right)$ to protect the specimens from oxidation. The specimens were machined in the form of $3 \mathrm{~mm}$ diameter cylindrical rods of $6 \mathrm{~mm}$ in length.

\footnotetext{
* GPM A30 is a powder metallurgy (PM) high-speed steel grade produced by Gloria Material Technology Corporation (GMTC)
} 
All specimens were austenitized rapidly $(3 \mathrm{~min})$ in the dilatometer at $1160{ }^{\circ} \mathrm{C}$ (this was the recommended austenitizing temperature for the alloys (Ref 10) and was chosen for subsequent tempering heat treatment), then quenched to ambient temperature. In this work, the tempering behavior of quench-treated specimens was investigated. The quench-treated specimens were heated at the rate of $20{ }^{\circ} \mathrm{C} / \mathrm{s}$ to the tempering temperature of $650{ }^{\circ} \mathrm{C}$, held at $650{ }^{\circ} \mathrm{C}$ for $1 \mathrm{~h}$, and then cooled at the rate of $20{ }^{\circ} \mathrm{C} / \mathrm{s}$ to ambient temperature; this was the first tempering cycle. The second and the third tempering cycles were repeated after the first tempering cycle. For the purpose of comparison, a single stage tempering treatment at $650{ }^{\circ} \mathrm{C}$ for $3 \mathrm{~h}$ was also carried out.

The corresponding microstructures were examined by using scanning electron microscopy (SEM) and transmission electron microscopy (TEM). Both specimens were cut from the dilatometer specimens. The specimens for scanning electron microscopy were mechanically polished and then etched in 5\% nital solution. Transmission electron microscopy (TEM) specimens were sliced from dilatometer specimens, thinned to $0.05 \mathrm{~mm}$ by abrasion on $\mathrm{SiC}$ papers, and twin-jet electropolished using a mixture of 5\% perchloric acid, $25 \%$ glycerol, and $70 \%$ ethanol at ambient temperature and $50 \mathrm{~V}$ polishing potential. The thin foils were examined using a JEM 2000EX transmission electron microscope operating at $200 \mathrm{kV}$ equipped with energy-dispersive X-ray spectrometer (EDS).

\section{Results and Discussion}

The SEM metallograph shown in Fig. 1(a) was obtained from the as-quenched sample and the composition analyses for different phases were as shown in Table 2. After quenching to ambient temperature, the microstructure consisted of martensite, retained austenite and undissolved coarse $\mathrm{MC}$ and $\mathrm{M}_{6} \mathrm{C}$ primary carbides. Carbide A had a similar amount of W, Mo, as one of $\mathrm{Fe}$, and was thus identified as $\mathrm{Fe}_{3}(\mathrm{~W}, \mathrm{Mo})_{3} \mathrm{C}$. Carbide $\mathrm{B}$ had more vanadium (about 60 at.\%), and was thus identified as VC. Matrix (marked C) had 81 at.\% Fe and 10 at.\% Co, so it was identified as mixed structures (martensite and retained austenite). Figure 1(b) shows an SEM metallograph (the first tempered specimen from $650{ }^{\circ} \mathrm{C}$ ), and the composition analyses for different phases are shown in Table 3. Carbide A had a similar amount of $\mathrm{W}, \mathrm{Mo}$ as one of $\mathrm{Fe}$, so it was identified as $\mathrm{Fe}_{3}(\mathrm{~W}, \mathrm{Mo})_{3} \mathrm{C}$. Carbide B had more vanadium (about 54 at.\%), so it was identified as VC. Matrix (marked C) had 79 at.\% Fe and 9 at.\% Co, so it was identified as mixed structures (martensite and retained austenite). Figure 1(c) shows an SEM metallograph (the second tempered specimen from $650{ }^{\circ} \mathrm{C}$ ), and the composition analyses for different phases are shown in Table 4. In carbide A, W and Mo occupied about 25 at.\% and $\mathrm{Fe}$ occupied about 57 at.\% (the ratio is 1:2), so it was identified as $\mathrm{Fe}_{4}(\mathrm{~W}, \mathrm{Mo})_{2} \mathrm{C}$. Carbide B had more vanadium (about 55 at.\%), so it was identified as VC. Matrix (marked C) had 83 at.\% Fe

Table 1 Chemical composition of GPM A30 high speed steels (wt\%)

\begin{tabular}{lccccccccccccc}
\hline $\mathbf{F e}$ & $\mathbf{C}$ & $\mathbf{S i}$ & $\mathbf{M n}$ & $\mathbf{P}$ & $\mathbf{S}$ & $\mathbf{N i}$ & $\mathbf{C r}$ & $\mathbf{M o}$ & $\mathbf{V}$ & $\mathbf{W}$ & $\mathbf{C o}$ & {$[\mathbf{N}]$} & {$[\mathbf{O}]$} \\
\hline Bal. & 1.28 & 0.44 & 0.28 & 0.021 & 0.022 & 0.22 & 4.18 & 5.00 & 3.20 & 6.13 & 8.73 & 794 & 174 \\
{$[\mathrm{~N}] \&[\mathrm{O}]: \mathrm{ppm}$} & & & & & & & & & & & & &
\end{tabular}

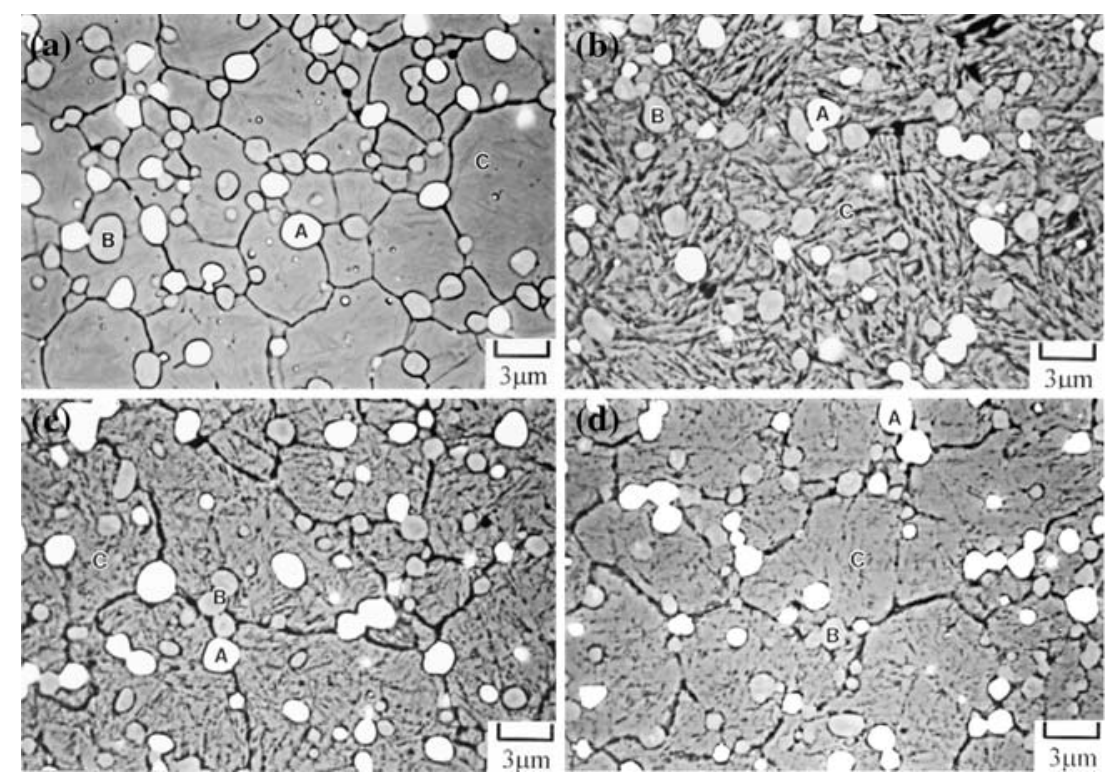

Fig. 1 Scanning electron metallographs taken from (a) the as-quenched specimen. (b) the first tempered (c) the second tempered (d) the third tempered specimens at $650{ }^{\circ} \mathrm{C}$ after quenching from $1160{ }^{\circ} \mathrm{C}$ 
Table 2 Average SEM/EDX analysis of the as-quenched specimen in primary carbides and the matrix (at.\%)

\begin{tabular}{lrrrrrr}
\hline & \multicolumn{7}{c}{ Compositions } \\
\cline { 2 - 7 } Phase & W & Mo & Cr & V & Co & Fe \\
\hline Carbide A & 22.76 & 22.00 & 5.60 & 4.70 & 5.05 & 39.89 \\
Carbide B & 12.59 & 15.44 & 6.55 & 59.79 & 0.98 & 4.66 \\
Matrix C & 1.59 & 1.72 & 4.88 & 1.24 & 9.48 & 81.10 \\
\hline
\end{tabular}

Table 3 Average SEM/EDX analysis of the first tempered specimen in primary carbides and the matrix (at.\%)

\begin{tabular}{lrrrrrr}
\hline & \multicolumn{7}{c}{ Compositions } \\
\cline { 2 - 7 } Phase & W & Mo & Cr & V & Co & Fe \\
\hline Carbide A & 23.22 & 22.14 & 5.84 & 4.24 & 5.29 & 39.28 \\
Carbide B & 10.61 & 14.40 & 6.63 & 54.23 & 1.46 & 12.67 \\
Matrix C & 1.65 & 2.28 & 6.50 & 1.81 & 9.19 & 78.56 \\
\hline
\end{tabular}

Table 4 Average SEM/EDX analysis of the second tempered specimen in primary carbides and the matrix (at.\%)

\begin{tabular}{lrrrrrr}
\hline & \multicolumn{7}{c}{ Compositions } \\
\cline { 2 - 7 } Phase & W & Mo & Cr & V & Co & Fe \\
\hline Carbide A & 13.33 & 12.86 & 5.79 & 2.62 & 7.73 & 57.67 \\
Carbide B & 10.09 & 13.88 & 7.42 & 54.66 & 1.98 & 11.97 \\
Matrix C & 0.70 & 0.74 & 4.66 & 0.92 & 10.34 & 82.63 \\
\hline
\end{tabular}

Table 5 Average SEM/EDX analysis of the third tempered specimen in primary carbides and the matrix (at.\%)

\begin{tabular}{lrrrrrr}
\hline & \multicolumn{7}{c}{ Compositions } \\
\cline { 2 - 7 } Phase & W & Mo & Cr & V & Co & Fe \\
\hline Carbide A & 22.31 & 22.23 & 5.79 & 4.24 & 5.58 & 39.86 \\
Carbide B & 11.43 & 15.67 & 6.87 & 57.16 & 0.97 & 7.91 \\
Matrix C & 1.65 & 1.84 & 5.06 & 1.34 & 9.68 & 80.42 \\
\hline
\end{tabular}

and 10 at.\% Co, so it was identified as mixed structures (martensite and retained austenite). Figure 1(d) shows an SEM metallograph (the third tempered specimen from $650^{\circ} \mathrm{C}$ ), and the composition analyses for different phases are shown in Table 5. Carbide A had a similar amount of W, Mo as one of Fe, so it was identified as $\mathrm{Fe}_{3}(\mathrm{~W}, \mathrm{Mo})_{3} \mathrm{C}$. Carbide $\mathrm{B}$ had more vanadium (about 57 at.\%), so it was identified as VC. Matrix (marked C) had 80 at.\% Fe and 10 at.\% Co, so it was identified as mixed structures (martensite and retained austenite). Some transmission electron micrographs presented in Fig. 2(a) and 2(b) show the metallographs corresponding to Fig. 1(a). From a bright field image (Fig. 2a), it could be seen that the matrix was twinned plate martensite, and the martensite plates were interspersed with the island morphology of retained austenite. Figure 2(b) was identified as retained austenite by the contrast of the dark field image in Fig. 2(a).

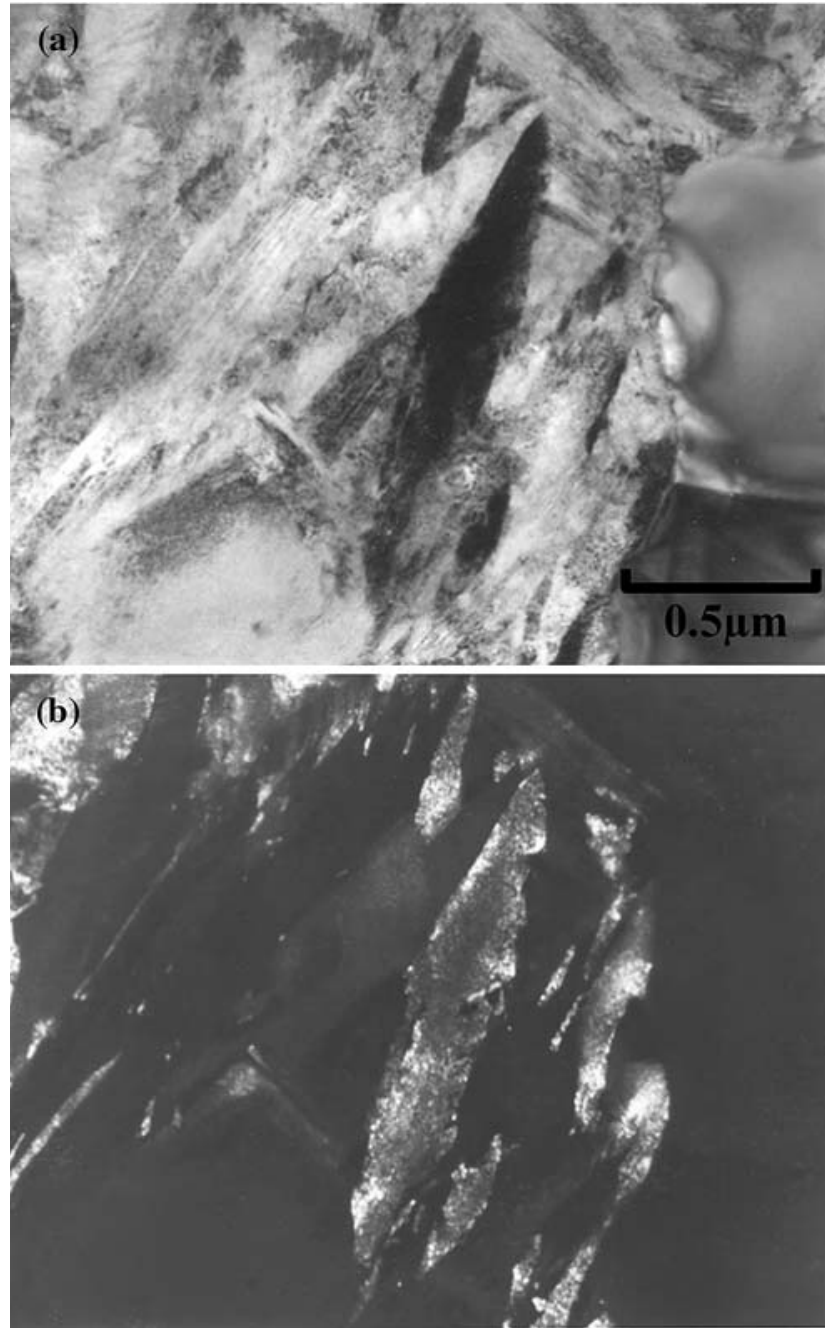

Fig. 2 Transmission electron micrographs of the as-quenched specimen showing the microstructure of retained austenite occurring in plate martensite matrix. (a) the bright field image; (b) the dark field image of retained austenite in (a)

Figure 3(a)-(d) show the dilatometric curves (the plots of relative length change versus temperature) for the quenchtreated specimens, which were subjected to repeated $(3 \times 1 \mathrm{~h})$ tempering at $650{ }^{\circ} \mathrm{C}$ with a cooling rate of $20^{\circ} \mathrm{C} / \mathrm{s}$. In the first tempering cycle, during the first isothermal holding at $650{ }^{\circ} \mathrm{C}$ for $1 \mathrm{~h}$, a rise in the relative length change in the corresponding dilatometric curve indicates that a significant amount of austenite has decomposed to ferrite and carbide. The subsequent cooling leads to martensitic transformation starting (Ms) at $350{ }^{\circ} \mathrm{C}$. In the second tempering cycle, as the specimen was repeatedly tempered at $650{ }^{\circ} \mathrm{C}$ for $1 \mathrm{~h}$, an increase in the relative length change in the corresponding dilatometric curve occurs, and the ensuing cooling brings about martensitic transformation beginning (Ms) at $365{ }^{\circ} \mathrm{C}$. However, during the second stage of cooling, the amount of martensite transformation is very small. In the third tempering cycle, as the specimen was repeatedly tempered at $650{ }^{\circ} \mathrm{C}$ for $1 \mathrm{~h}$, the negligible increase in the relative length change in the corresponding dilatometric curve indicates that all of the austenite has almost been eliminated, and the ensuing cooling brings about martensitic transformation beginning (Ms) at $375{ }^{\circ} \mathrm{C}$. However, during the final stage of 

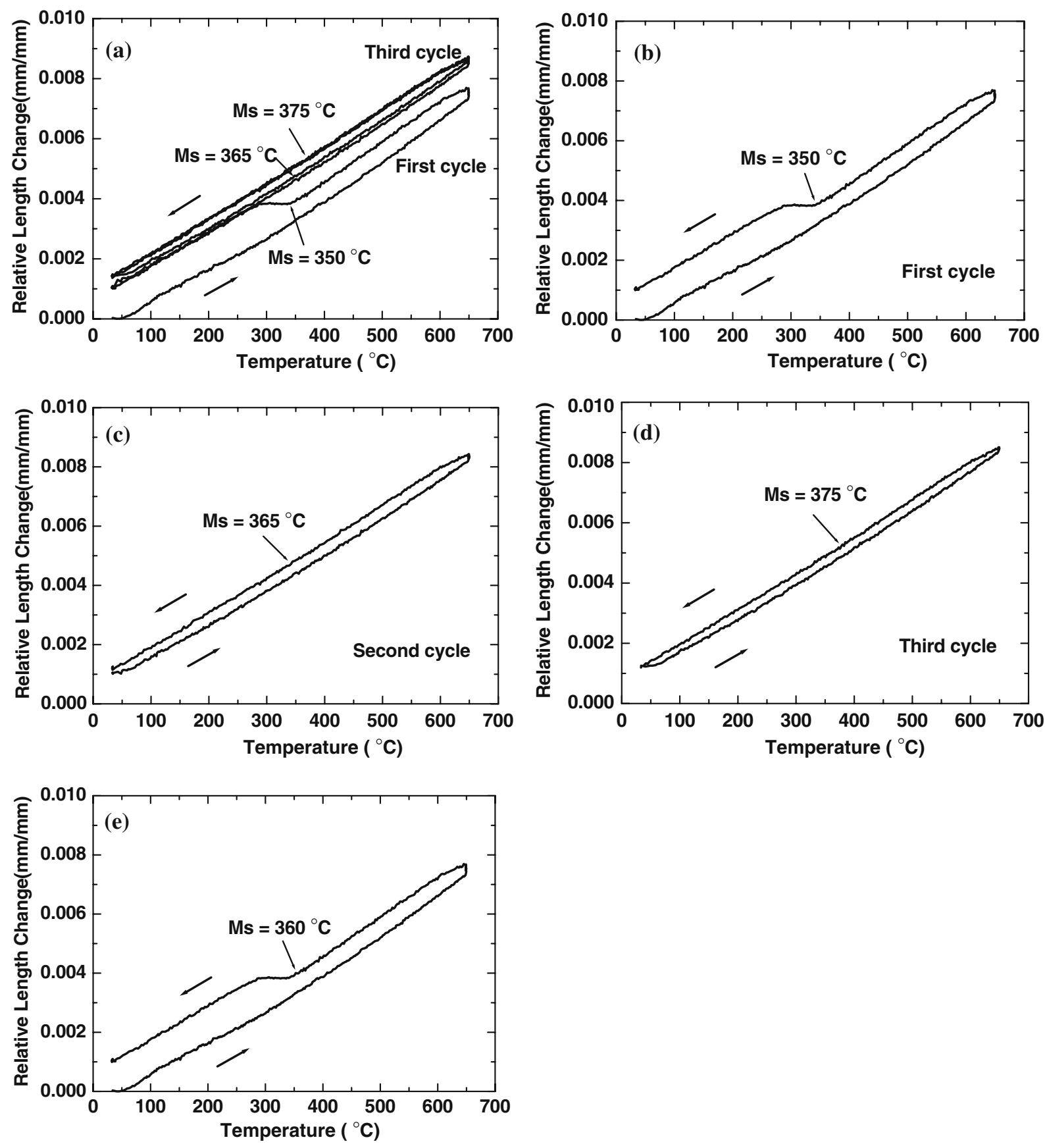

Fig. 3 Dilatometric curves for the tempered specimens. (a) the triple cycles tempering (b) the first cycle tempering (c) the second cycle tempering (d) the third cycle tempering (e) the single long-time cycle tempering

cooling, the amount of martensite transformation is quite small. On the other hand, if the quench-treated specimen is tempered at $650{ }^{\circ} \mathrm{C}$ for $3 \mathrm{~h}$, the corresponding dilatometric curve, as shown in Fig. 3(e) for the single tempering cycle, indicates that the Ms temperature is about $360{ }^{\circ} \mathrm{C}$, and that a considerable amount of martensite forms during the final cooling. It demonstrates that decomposition of austenite is sluggish and cannot be complete after the isothermal holding at $650{ }^{\circ} \mathrm{C}$ for $3 \mathrm{~h}$. It is apparent that the state of austenite prior to the diffusional transformation at $650{ }^{\circ} \mathrm{C}$ is of decided importance. The results imply that for the quench-treated specimen, the use of double or triple tempering (two or three repeated cycles at $650{ }^{\circ} \mathrm{C}$ for $1 \mathrm{~h}$ ) has an advantage in terms of the diffusional decomposition of austenite over single tempering (only one cycle at $650{ }^{\circ} \mathrm{C}$ for $3 \mathrm{~h}$ ). Direct observation of the austenite/martensite interface has provided evidence that the invariant-plane-strain shape deformation of the prior martensitic transformation extends accommodation defects into the adjacent retained austenite, which favors further transformation in the subsequent tempering operations. The transmission electron micrographs shown in Fig. 4(a) and 4(b) were taken from the quench-treated specimen; they clearly illustrate that the plastic relaxation brings about dislocation clusters and planar faults within the retained austenite adjacent to the plate martensite. 
The tempered structures were examined, and several representative micrographs are displayed as follows: The microstructural degeneration of the heavily twinned plate martensite and the adjacent austenite after one-stage $(1 \times 1 \mathrm{~h})$ tempering at $650{ }^{\circ} \mathrm{C}$ is illustrated in Fig. 5. In this condition, nano-scaled fine carbides are found to be embedded in the plate martensite and austenite matrix. A number of extremely fine
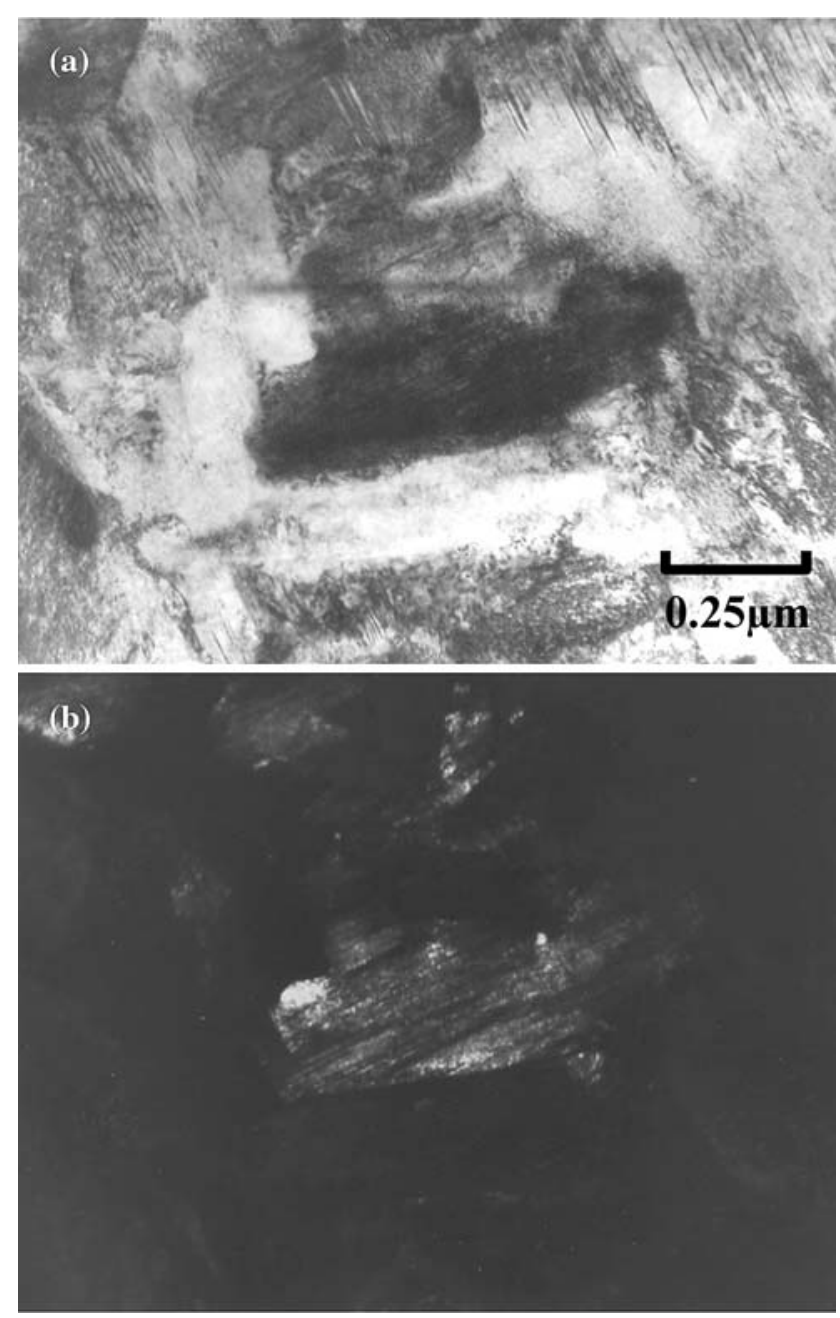

Fig. 4 Transmission electron micrographs showing the microstructure of accommodation defects within austenite
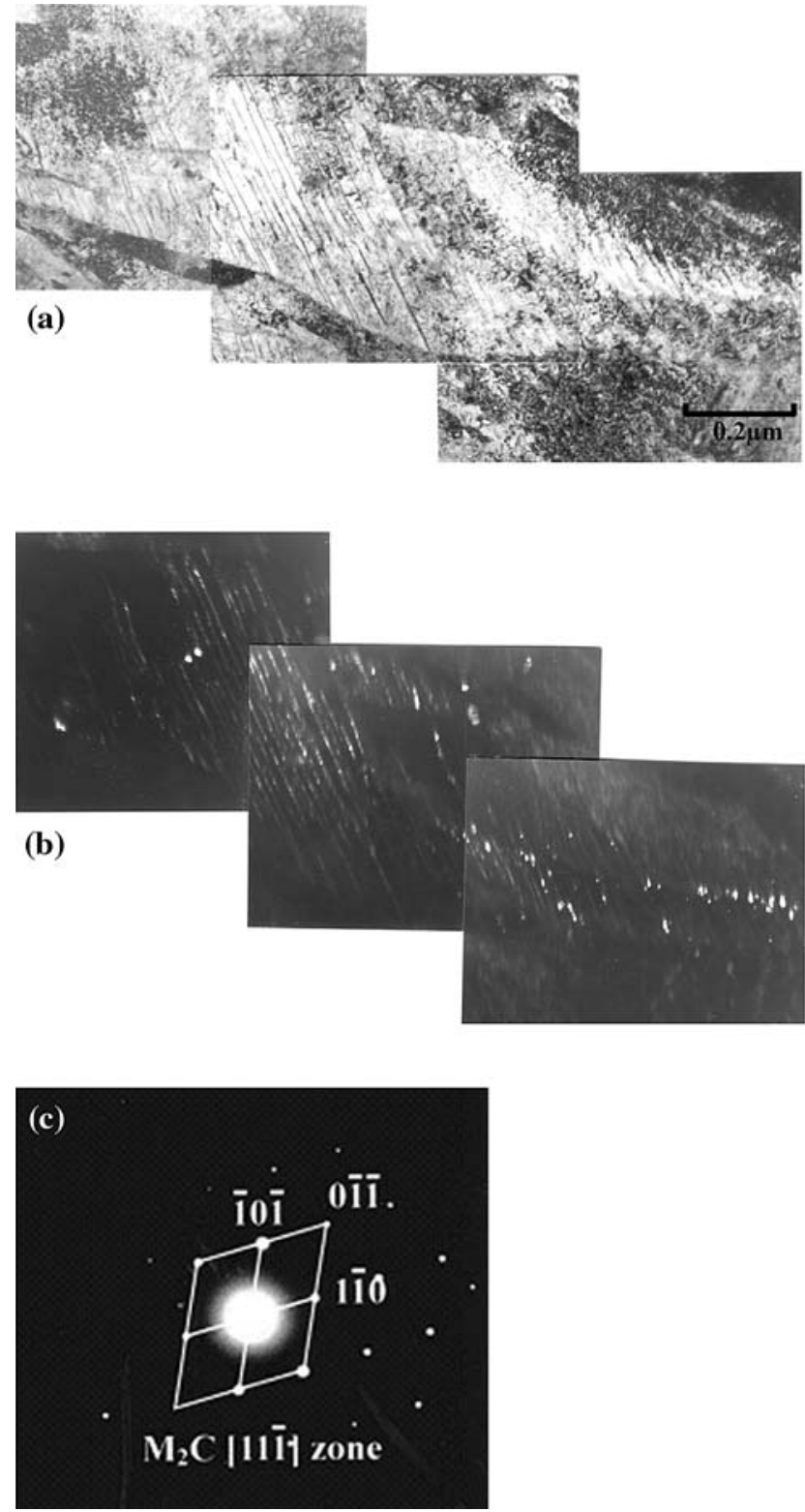

Fig. 6 Transmission electron micrographs showing the microstructure of $\mathrm{M}_{2} \mathrm{C}$ carbide precipitates at internal twin boundaries. (a) the bright field image; (b) the dark field image of $\mathrm{M}_{2} \mathrm{C}$ carbide in (a); (c) diffraction pattern of $\mathrm{M}_{2} \mathrm{C}$

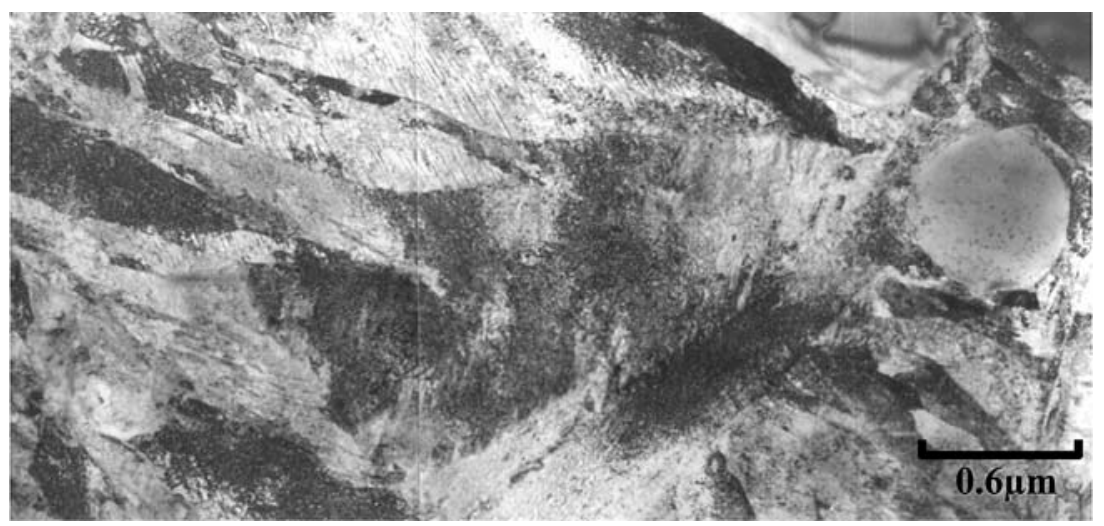

Fig. 5 Transmission electron micrograph showing the microstructure of the degenerated structures in twinned plated martensite and adjacent austenite 

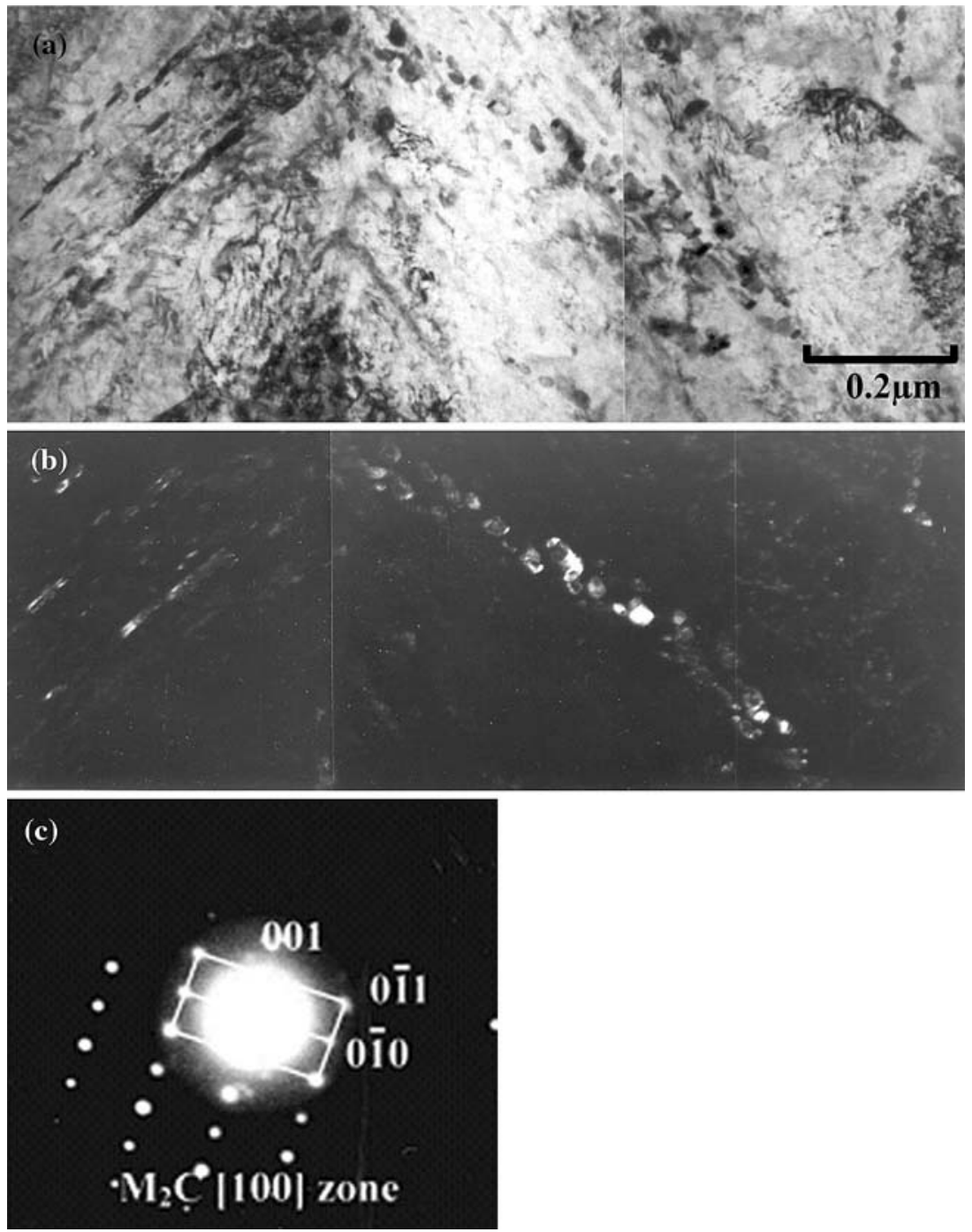

Fig. 7 Transmission electron micrograph showing the microstructure of carbides in the diffusionally decomposed austenite areas. (a) the bright field image; (b) the dark field image of $\mathrm{M}_{2} \mathrm{C}$ carbide in (a); (c) diffraction pattern of $\mathrm{M}_{2} \mathrm{C}$

needle-shaped and rod-shaped $\mathrm{M}_{2} \mathrm{C}$ precipitate on the internal twin boundaries of the plate martensite and in the matrix between the twin boundaries were revealed (Fig. 6). Figure 7 shows TEM micrographs for the products from the diffusionally decomposed austenite area during the second stage $(2 \times 1 \mathrm{~h})$ isothermal holding; the nanostructures are mostly composed of $\mathrm{M}_{2} \mathrm{C}$ carbide, and their morphologies are rod-shaped. It was also found that the $\mathrm{M}_{2} \mathrm{C}$ precipitates coarsen and cluster little by little during this tempering stage. After triple-stage $(3 \times 1 \mathrm{~h})$ tempering at $600{ }^{\circ} \mathrm{C}, \mathrm{M}_{7} \mathrm{C}_{3}$ carbides were found to replace $\mathrm{M}_{2} \mathrm{C}$ carbides at the internal twin boundaries of the plate martensite, as shown in Fig. 8. It is suggested that the $\mathrm{M}_{2} \mathrm{C} \rightarrow \mathrm{M}_{7} \mathrm{C}_{3}$ transformation is in the form of ,separate nucleation'; as a portion of the $\mathrm{M}_{2} \mathrm{C}$ carbides dissolve in the ferrite matrix, the alloy elements of $\mathrm{M}_{7} \mathrm{C}_{3}$ carbides are separately nucleated at new sites gradually. As for the carbides in the diffusionally decomposed austenite, the same trend, that $\mathrm{M}_{7} \mathrm{C}_{3}$ carbides replace $\mathrm{M}_{2} \mathrm{C}$ carbides by degrees, was also found. It is worth noting that a striking feature in Fig. 9, nearby the diffusionally decomposed austenite area, reveals that the spacing and the morphology of tempered twinned plate martensite become broader and irregular in shape. That the tempered martensite can form in irregular shapes during this stage may be attributed to the effect of the clustering and coarsening of $\mathrm{M}_{2} \mathrm{C}$ precipitates immediately at twin boundaries of the plate martensite.

\section{Conclusions}

An investigation of the tempering response in quenchtreated specimens of GPM A30 high speed steel was conducted. Based on scanning electron metallography, dilatometry, and transmission electron microscopy, the important findings in this work are summarized as follows:

(1) The results indicate that a more complete transformation of retained austenite can be obtained by three-stage $(3 \times 1 \mathrm{~h})$ tempering at $650{ }^{\circ} \mathrm{C}$ than by single-stage $(1 \times 3 \mathrm{~h})$ tempering at $650^{\circ} \mathrm{C}$.

(2) Transmission electron microscopy observation of the austenite/martensite interface has provided evidence that the invariant-plan-strain shape deformation of the prior martensitic transformation extends accommodation 

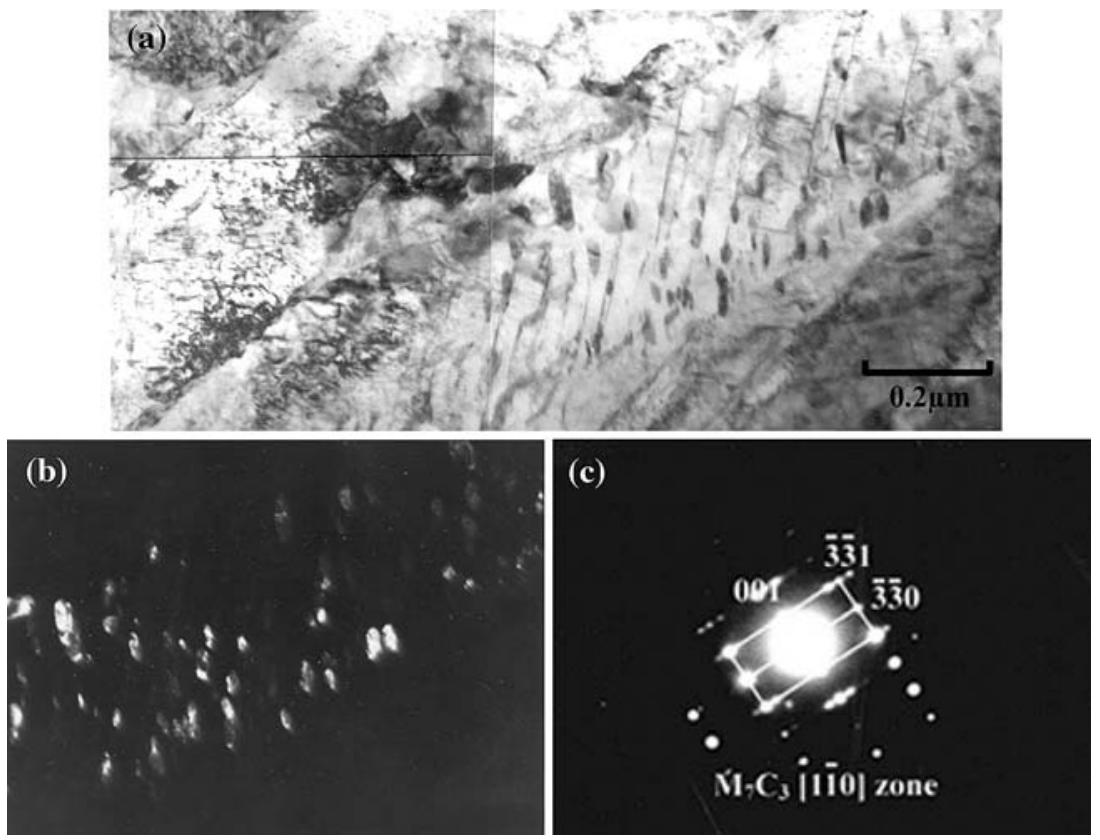

Fig. 8 Transmission electron micrographs showing the microstructure of $\mathrm{M}_{7} \mathrm{C}_{3}$ carbide forming at the internal twin boundaries. (a) the bright field image; (b) the dark field image of $\mathrm{M}_{7} \mathrm{C}_{3}$ carbide in (a); (c) diffraction pattern of $\mathrm{M}_{7} \mathrm{C}_{3}$

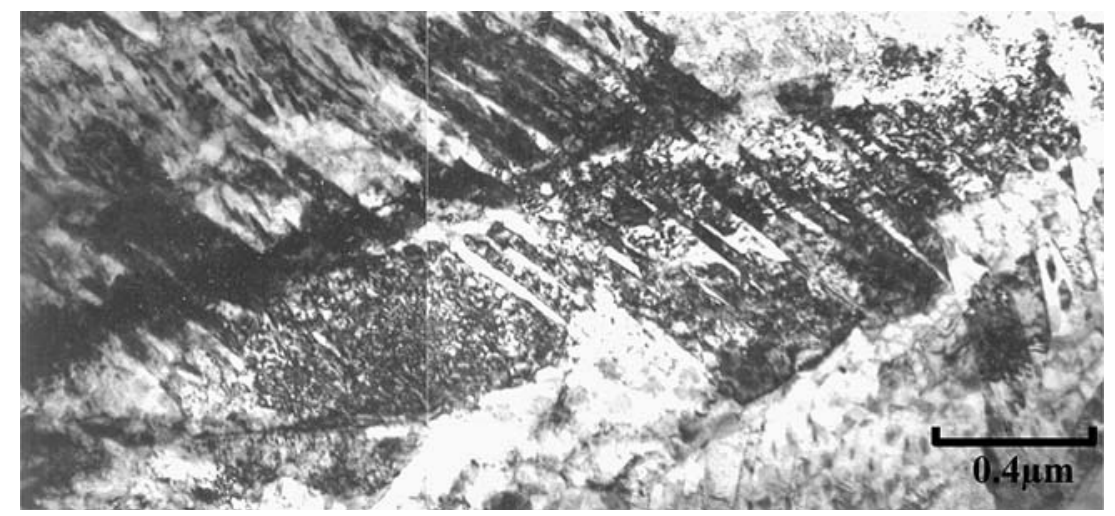

Fig. 9 Transmission electron micrograph showing the microstructure of irregular-shaped tempered twinned plate martensite formed in the specimen after the third stage $(3 \times 1 \mathrm{~h})$ tempering at $650{ }^{\circ} \mathrm{C}$ and cooling to room temperature

defects into the adjacent retained austenite, which enhances further transformations in the subsequent tempering treatments.

(3) In the three-stage $(3 \times 1 \mathrm{~h}) 650{ }^{\circ} \mathrm{C}$ tempered specimen, $\mathrm{M}_{7} \mathrm{C}_{3}$ carbides were found to replace $\mathrm{M}_{2} \mathrm{C}$ carbides at the internal twin boundaries of the plate martensite; in the diffusionally decomposed austenite areas, the same trend, that $\mathrm{M}_{7} \mathrm{C}_{3}$ carbides replace $\mathrm{M}_{2} \mathrm{C}$ carbides by degrees, was also found.

\section{References}

1. F.B. Pickering, Materials Science and Technology: A Comprehensive Treatment, Vol 7, R.W. Cahn, P. Haasen, and E.J. Kramer, Ed., WileyVCH Publisher, New York, Dec., 1991, p 593-597

2. T. Mukherjee, Physical Metallurgy of High-Speed Steels, Proc. Conf. on Materials for Metal Cutting, Apr. 14-16, 1970, iron and steel inst.
3. O.N. Mohanty, On the Stabilization of Retained Austenite: Mechanism and Kinetics, Mater. Sci. Eng. B: Solid State Adv. Technol, 1995, B32(3), p 267-269

4. L.E.G. Cambronero, E. Gordo, J.M. Torralba, and J.M. Ruiz-Prieto, Comparative Study of High Speed Steels Obtained Through Explosive Compaction and Hot Isostatic Pressing, Mater. Sci. Eng. A, 1996, A207(1), p 36-45

5. L.S. kremnev, Theory of Alloying of High Speed Steels, Met. Sci. Heat Treat, 1991, 33(5-6), p 428-434

6. R. Wilson, Metallurgy and Heat Treatment of Tool Steels, McGrawHill Book Co. Ltd, New York p 163-194

7. George A. Roberts and Robert A. Cary, High Speed Steels, Tool Steels, 4th ed., American Society for Metals, Inc., 1980, p 627-761

8. G. Hoyle, High Speed Steels, Butterworth Press, Boston

9. R.W.K. Honeycombe and H.K.D.H. Bhadeshia, Steels: Microstructure and Properties, Edward Arnold, London $\mathrm{p} 171$

10. R. Wang, H.O. Andren, H. Wisell, and G.L. Dunlop, Role of Alloy Composition in the Precipitation Behavior of High Speed Steels, Acta Metall. Mater., 40(7), Jul., 1992, p 1727-1738 